\title{
Optical Remote Sensing for Biophysical Characterisation in Forests: A Review
}

\author{
Indu Indirabai ${ }^{1 *}$, M.V. Harindranathan Nair ${ }^{1}$, Jaishankar. R. Nair ${ }^{2}$, Rama Rao Nidamanuri ${ }^{3}$ \\ ${ }^{1}$ School of Environmental Studies, Cochin University of Science \& Technology, Kochi, Kerala, India. \\ ${ }^{2}$ C.V Raman Laboratory of Ecological Informatics, IIITM-Kerala, Technopark Campus, \\ Thiruvananthapuram, Kerala, India. \\ ${ }^{3}$ Department of Earth \& Space Sciences, Indian Institute of Space Science and Technology, \\ Valiamala, Thiruvananthapuram, Kerala, India.
}

\begin{abstract}
The estimation of the forest biophysical attribute is of great importance now a days because the forest plays a significant role in the global climate change and the ecosystem dynamics. Numerous approaches and data sources have been used to estimate the biophysical parameters. In this paper, an attempt has been made to review the role of optical remote sensing for biophysical characterisation in forests. The applications of multispectral as well as the hyperspectral imagery in forestry is pointed out. The given review elucidates different methods of conventional forest mensuration and a clear detailed description about the advantages and limitations of the conventional techniques. It was clear from the review that the limitations of the conventional techniques lead to the development of most advanced technologies including photogrammetry, remote sensing, active remote sensing systems etc. The integration of the advanced technologies along with conventional field measurements can also be used for the accurate and effective measurement of the forest parameters. The limitations of optical remote sensing in the estimation of forest structural parameters lead to the advancement of active remote sensing forest mensuration. The need for the active remote sensing is also demonstrated in the review.
\end{abstract}

Keywords: Remote Sensing, Multispectral Remote sensing, Biophysical parameters, Hyperspectral imagery.

\section{INTRODUCTION}

Biophysical parameters play an important role in determining the condition, characteristics, and classification of the forest resources. In the case of researches related to ecology and for the effective forest management, accurate information on the biochemical, physiological and the forest structural parameters are very substantial. Acquisition of biophysical parameters for forest management, inventory, biophysical modelling, and habitat analysis is a matter of concern in the forest researches. The quantification, mapping, monitoring and the estimation of forest parameters are now central issues due to the importance of forest conservation and the biomass is a renewable energy source in many countries of the world. The estimation of forest parameters is a challenging task, especially in areas with complex stands and varying environmental conditions which requires accurate and consistent measurement methods. For conserving the forest resources and utilizing them effectively, it is vital to have detailed knowledge of its distribution, abundance, and quality.

\subsection{Conventional methods for biophysical parameter estimation}

The measurements of trees and forests are essential for the effective utilization of the forest resources as well for understanding the development and growth of the forests. Lot of traditional methods are used for estimating the forest parameters including canopy height, diameter, biomass, canopy etc. For measuring canopy heights, laser range finders. Clinometer. Measuring tapes, poles, simple distance prisms etc are usually used [1], [2], [3]. These methods require skilled, motivated and experienced men for the accurate measurements and also many a times the underestimation and over estimation of tree heights occur in most cases [4]. Traditional methods of forest parameter estimation are effective in case of local forest area but cannot be applied in large scale forest inventory which require periodic update of the forest data. They are too expensive, time consuming and cannot cover the entire and remote forest.

For measuring diameter, instruments like dendrometer [5], tree calipers, tape, Biltimore stick and relaskop are usually used in the field but the main concerns are based on the accuracy, economy and efficiency [6]. But they showed some statistically significant variations in other related parameters including tree volume [7], [8]. Forest characteristics and measurement distance play a key role in remote diameter measurement accuracy [9]. Tree measurements usually involve breaking down of individual trees into various classes of material and the development of giant tree table [10]. West incorporated the basic measurements in forests including the various parameters of forestry and the factors which influence the parameters in the forest, the interdependence of those parameters and also the basic techniques which were used in the forest measurements in the past [11]. By using cross sectional photogrammetric and densitometric methods, canopy profiles can be estimated [12]. An insight of the technologies to be developed for the betterment of the forest mensuration, the limitations of the conventional methods of forest mensuration and the need for proper integration of traditional measurement methods with current technologies were well incorporated by [13]. 
In some studies, field methods for sampling tree heights for tropical forest biomass by testing different strategies of sampling trees top, produces locally derived models [14]. Growing stock variation in pure coniferous forest types of Garhwal Himalaya of Uttarakhand using growing stock estimation method provide valuable information about stand biomass and carbon flux [15].Biomass can be estimated by means of direct methods which involves the harvesting of all the trees and measurements of the weight of the trees [16], [17], [18],[19], [20], [21], [22], [23], [24] but it is time consuming, destructive and costly. Biomass estimation can also be done by non-destructive methods but requires the trees to be harvested and weighted [25] Non-destructive method including climbing the tree and also by allometric equation [26], [27], [28] requires lot of manual work and are time consuming. Thus, the conventional methods have proved that they are environmentally unfriendly and time consuming in most cases of forest parameter estimation.

\section{REMOTE SENSING TECHNOLOGY FOR THE BIOPHYSICAL PARAMETER ESTIMATION}

\subsection{What is remote Sensing?}

Remote Sensing is the science and art of obtaining physical characteristics of an object, area or phenomenon through the analysis of data acquired by a device that is not in contact with the object by measuring the reflected and emitted radiations at a distance from the targeted area [29] Remote sensing technique provide images of the earth surface in various wavelength region of the electromagnetic spectrum. Characteristics of the remote sensing image depends on the region of wave length it represents in the electromagnetic spectrum. Remote sensing is the measurement of electromagnetic radiations reflected or emitted from an object [30], [31].

Objects emits or reflects different amounts of energy in various bands of the electromagnetic spectra which depends upon the physical, chemical properties of the material, surface roughness, angle of incidence, intensity and wavelength of the radiations [32]. There are various stages in remote sensing (Figure 1) including

\section{Emission of Electromagnetic Radiation}

The first requirement of remote sensing is the energy source to illuminate the target and the energy is in the form of electromagnetic radiation which has two characteristics wavelength and frequency which are related by the general equation $\mathrm{c}=v \lambda$, where $\mathrm{c}$ is the velocity of light, $v$ is the frequency and $\lambda$ is the wavelength of the electromagnetic radiation. In remote sensing, electromagnetic waves are divided based on their wavelength location within the electromagnetic spectrum. Most common remote sensing systems operate in the visible, Infrared or microwave portions of the electromagnetic spectrum [29].

Sun is the most common source of remote sensing, and the remote sensing systems that measure the naturally available energy are called passive sensors. Active sensors provide their own source of illumination and therefore is independent on time, day or season.

\section{Transmission of energy from the source to surface of the earth as well as the energy interactions in the atmosphere}

The radiations interact with the atmosphere before reaching the surface of the earth, which have profound effect on the intensity and spectral composition of radiation due to the atmospheric scattering and absorption phenomena. Scattering occurs due to the unpredictable diffusion of radiation by particles present in the atmosphere as the electromagnetic radiation is transmitted. The three types of scattering usually occur are Rayleigh scattering, Mie scattering and nonselective scattering. Atmospheric absorption causes the molecules in the atmosphere to absorb energy at various wavelengths results in the effective loss of energy to atmospheric constituents and the most common absorbers of solar radiation are ozone, carbon dioxide and water vapour. Certain wavelengths in which the atmosphere is particularly transmissive of energy are referred to as atmospheric windows.

\section{Interaction of Electromagnetic radiation with the earth's surface including reflectance and transmittance.}

When electromagnetic energy is incident on earth surface feature, it undergoes reflection, absorption and transmission. Most of the remote sensing systems operate in the wavelength in which the reflected energy predominates. The reflectance characteristics of surface features depends on the incident energy that is reflected. Which is measured as the function of wavelength and is called spectral reflectance curve. Spectral reflectance curve gives an idea of the spectral characteristics of an object and the earth surface features can be studied based on the spectral characteristics.

\section{Transmission of energy from the object to the sensor}

Sensor which is highly sensitive to all wavelengths collected the electromagnetic energy that has been emitted or reflected from the target. Remote sensing platforms commonly used are ground level remote sensing, aerial remote sensing, space borne remote sensing which may consists of stepladders helicopters, conventional aircraft, uninhabited aerial vehicles and satellites.

\section{Data processing and supply system}

The data obtained from the sensors is processed into an interpretable format with the help of additional reference data to extract information about the target. Distribution of data after the collection may vary, some sources provide the data within 24 hours of the image acquisition.

\section{Analysis of data by different users}

Data will be provided to the multiple users for the interpretation of the information available in the data at a faster rate and with less expense for various decision-making processes and further implementations. Thus, remote sensing has become an essential tool in many interdisciplinary aspects of science and various other fields. 


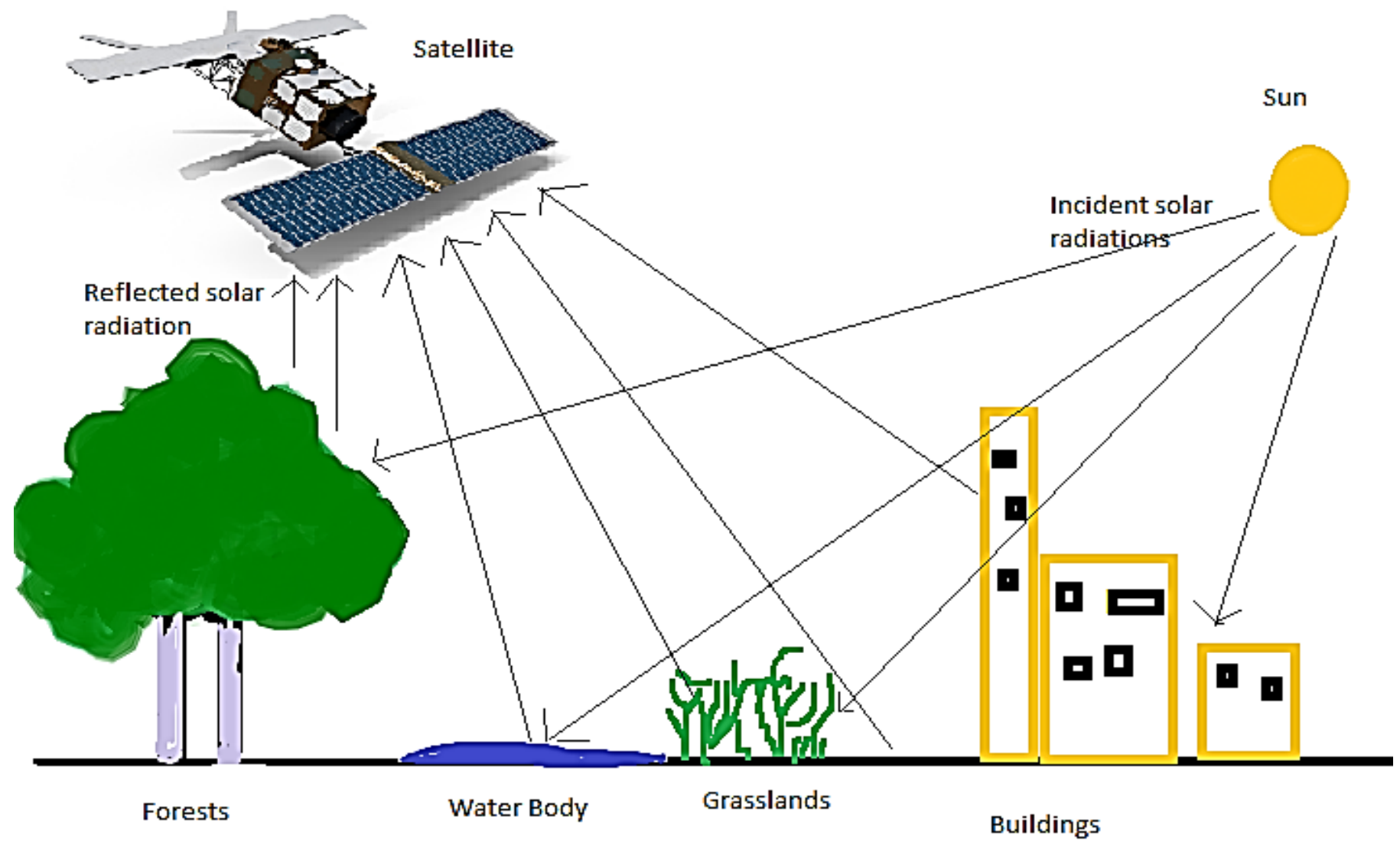

Figure 1: Stages in Remote Sensing

\subsection{Types of remote sensing}

Based on the source of energy, remote sensing systems are classified into passive remote sensing systems and active remote sensing systems. Passive systems measure naturally available energy from Sun and can only takes place in the presence of sunlight. The active systems provide their own source of energy and can measure energy irrespective of time day or season [33].

Several remote sensing satellites are currently available in which they are classified based on the wavelength bands, spatial resolution, coverage etc. In terms of spatial resolution, the remote sensing systems are classified into low resolution systems, medium resolution systems and high-resolution systems, and in terms of the spectral regions used in the data acquisition, they are classified into optical imaging systems, thermal imaging systems and Synthetic aperture radar. The range of electromagnetic spectrum in which the optical remote sensing systems operates are visible, infrared, near infrared, middle infrared, and short infrared regions. Optical remote sensing systems are classified into panchromatic imaging systems in which the sensor is a single channel detector (IKNOS PAN), multispectral imaging systems (Landsat TM, SPOT etc) and hyperspectral imaging systems (AVIRIS, Hyperion). Active remote sensing systems include radar and Light detection and ranging- LiDAR.

\subsection{Advantages of remote sensing}

Remote sensing has various advantages including large area coverage, repetitive coverage and easy collection of data over a variety of scale and resolutions. A single remote sensing image can be utilised for unlimited number of applications and can be easily processed and analysed by computer software. The data can overcome the limitations in the case of conventional field methods. Identification and location of floods and fire over large area, availability of colour composite maps are other advantages. Images can be archived or reused to check the repeatability of a method, rapidly increasing sophistication of satellites, availability of unlimited number of sample points and variety of complementary sensors are other important advantages. Some of the other benefits are the good archive of historical data, cost effective and map accurate data and remote sensing technology enable to combine the satellite images with other digital data as well as stereo viewing.

\subsection{Applications of remote sensing}

Following are some of the major area in which remote sensing is useful

\section{Forestry and ecosystem}

- Density mapping

- Forest cover mapping

- Species identification 
- Biophysical parameter estimation

- Carbon budget estimation

- $\quad$ Forest fire mapping

\section{Land use land cover mapping}

Remote sensing can be used to estimate up to date land cover maps and patterns so as to enable the regional planners and administrators to frame policy matters. It can also be used for wildlife protection, natural resource management and study related to land encroachment.

\section{Agriculture}

The application of remote sensing in agriculture are varied including crop assessment, crop type classification, precision farming, crop condition assessment, yield estimation etc.

\section{Geologic and Soil mapping}

Satellite images have the advantage of large area synoptic coverage to examine geological portrayal of earth on regional basis. Exploration of minerals and energy sources on an extensive scale is possible. Mapping of morphological features like streams, mountain ranges, lineaments, lithological mapping etc can also be done. Soil mapping, moisture assessment, wetland mapping, sedimentation mapping, collection of soil information and interpretation of soil is possible with the remote sensing system.

\section{Hydrology}

Application of remote sensing in hydrology includes water pollution detection, lake eutrophication assessment, flood damage estimation, watershed mapping and management, ground water targeting etc.

\section{Urban and regional planning}

For urban planning continuous acquisition of data to formulate policies is vital in which remote sensing can play major role by estimating population, assisting housing quality studies, traffic and parking studies, transportation route location, power plant siting, commercial site selection, transmission line location, urban change detection etc.

\section{Ocean applications}

Ocean applications of remote sensing include water quality monitoring, navigation routing, costal vegetation mapping, oil spill assessment, storm forecasting etc.

The other major application of remote sensing includes natural disaster assessment, archaeological applications, environmental assessment, wild life ecology assessment etc

\section{OPTICAL REMOTE SENSING IN FORESTRY APPLICATIONS}

In the case of forestry, the strategic and operational planning is required for obtaining information of forest resources and management practices. Traditional forest inventories which can extent only to some limited spatial coverage are designed to obtain information associated with timber harvesting and restricted only to few locations [34] But the accuracy and consistency of the measurements and interpretations along with the high cost by the traditional field inventories are a common challenge [35]. In order to characterise the quality and quantity of forests including stand structure, productivity and composition of the forest ecosystem, consistent and enhanced information is vital. This is also necessary for developing and improving the management strategies related to biodiversity, forest health and biophysical parameter estimations [34], [36]. The role of remote sensing technologies is significantly increasing in the case of forest inventories and practices since they can provide enhanced information directly or indirectly as well as collecting forest resource information with high spatial accuracy which can enable tactical, strategic and operational forest planning and management [34] [37].

Remote sensing technology can offer data sets which are less expensive compared to traditional methods and provides a direct means of understanding and analysing the forest conditions globally through so many applications including tree species identification, studying harvested areas, timber cruising and assessing forest health conditions [29]. Remote sensing images on classification analysis of spectral response patterns can give information of forest and enable the estimation of forest structural variable, and therefore remote sensing can be considered as the essential component, decisive tool, and a critical part of the technological approach which is vital for satisfying the large and growing requirements of forest management [38]. For national forest inventories, remote sensing has applications including observation estimation and mapping of wide range of forest resource variables [39]. Remote sensing of temporal and boreal forests in the visible and near infrared regions for about 25 years of satellite remote sensing research are well incorporated in [40]. Infrared imagery showed to the best technique for forest studies particularly for inventories, management, monitoring and detection [41]. Remote sensing technology can address the needs including prediction, identification of biophysical characteristics of species, habitats, species richness as well as distribution [42]. Remote sensing on integration with artificial neural networks was utilized for mapping tropical forest structure in South Eastern Madagascar [43]. Linear regression models from hyperspectral remote sensing named HyMap imaging spectrometer estimated leaf area index and crown volume with good accuracy [44].

Spatial extent of forest cover, forest type and the biophysical and chemical properties of forest can be assessed by remote sensing [45]. Stand biomass estimation method by canopy coverage in arid area of Western Australia by remote sensing provided considerable accuracy [46]. Several studies were there which reveals the potential of remote sensing to assess characteristics of active fires, ecological responses of fire, effects on ecology after fire etc [47], [48], [49], [50], [51]. Remote sensing can estimate the above ground biomass (AGB) with high accuracy and low cost [52], [53], [54]. Remote sensing methods can effectively be used to estimate the forest parameters, compared to the conventional techniques [55], [56], [57]. The remote sensing techniques can be successfully used for the retrieval of structural parameters for a wide range of analysis [58], [29]. The forest dynamics in Eastern Ghats of Tamilnadu between 1990 and 2003 were assessed using TM, IRS, LISS III and the trends and the basics for further studies 
were elucidated [59]. The use of remote sensing as an alternative tool to ground based surveys ensures the sustainability of forest ecosystem. Advanced remote sensing technologies and their applications in forestry are mentioned in the following sections.

\subsection{Application of multispectral imagery}

Optical remote sensing technologies can successfully measure the horizontal distribution of forests [60], [61]. Multispectral remote sensing has been explored extensively for biophysical characteristaion of forests across various sites [61], [62]. Moderate resolution multispectral remote sensing data such as Landsat ETM+, Landsat 8OLI has been extensively used for measuring the horizontal structure and distribution of forest canopies, stress, forest community delineation and biomass [63], [64], [65], [58], [29]. Multispectral remote sensing data can be used to obtain some biophysical attributes at local to global scales. Most of these operational products use data from coarse resolution satellite such as MODIS, AVHRR, SPOT Vegetation which provide standard products available at various scales on daily, weekly or monthly basis. Multispectral remote sensing has been explored and successfully applied in large forests area. Several studies showed that multispectral data can be used to obtain relevant biophysical attributes. Landsat 8OLI can provide opportunities for analysing the contribution of forest ecosystem to carbon cycle by the estimation of above ground biomass (AGB) [63]. Optical remote sensing technologies have extensive application in the extraction of the horizontal parameters of forest with high spatial resolution.

Passive Remote Sensing in data are based on different resolutions and certain limitations were there, when applied in the forestry application based on the spatial resolution [29], [66], [61], [67]. Multispectral and hyperspectral sensors can be used in the forestry application. Contextual forest attributes can be effectively done based on passive remote sensing Basal area and stand density were measured using ANN, K nearest neighbour approaches [43], [68]. Leaf Area Index (LAI) was found to measure using VI and ASTER data and the same can be utilized for the estimation of tree biomass [69], [70]. Empirical modelling varies between sites and species and therefore could not be applied on a specific site [71], [52]. LAI determined by methods like root mean square and stand error, bi variation regression analysis correlation, SR and NDVI, multiple regression, least square regression, but were found to be site specific [72], [73], [74], [75], [76]. Timber volume were estimated using KNN methods [77], [78]. Bio struct model were used for the estimation of volume and biomass. For the estimation of the above ground biomass, some of the common methods used included multiple regression, ANN, regression succession forest method, Mature forests [52], [53], [54], but it was found to site specific. Tree level structural characteristics were found to be measured using high spatial resolution satellite images.

Remote sensing methodology focussed on the contextual forest attributes as well as location based attributes, but the limiting factors include the saturation of satellite signals in mature forests, cost etc [60]. Passive optical sensors have limitations in operational forest inventory [79], [80], [81]. Ecosynth methodology as a new aerial remote sensing system, enabling routine and inexpensive aerial $3 \mathrm{D}$ measurements of canopy structure and spectral attributes. The ability to observe canopy phenology in $3 \mathrm{D}$ at high temporal resolution represents a breakthrough in forest ecology [82].

Landsat imagery were widely uded in estimating timber volume, assessing forest wildlife habitat, successional stage, rare and endangered spceies and characterisstics of species [83], [84]. High resolution multispectral sensors like Quickbird, IKNOS and SPOT 5 allow a more detailed geometrical analysis of the forest parameters [85], [86]. It is possible to map forest health using spectral and textural information extracted from SPOT-5 satellite images [87].

\subsection{Application of hyperspectral imagery}

To understand the changes in the conditions and amount of vegetation, remote sensing imageries from airborne and space borne sensors can play a significant contribution [88]. Hyperspectral data which have abundant spectral content have potential to measure the complex forest ecosystems and identification of individual tree species along with fine spectral and spatial details [89], [90]. Several studies have been reported the application of hyperspectral imagery in forestry [12]. Optical indices which are sensitive to both chlorophyll content and canopy structure are useful in understanding whether the forests are healthy or stressed, forest decline, for modelling forest nitrogen content, leaf economic spectrum and leaf development [91], [92], [93], [94]. Hyperspectral remote sensing can acquire very narrow typically 200 or more bands thus obtaining contiguous reflectance bands for every pixel in the scene [95] thereby enabling in depth analysis of the forest species. Hyperspectral remote sensing can offer enhanced spectral information which can be utilized for analysing the forest health conditions, forest fire etc to a great extent.

\section{DISCUSSION}

Forest measurements using field survey techniques are found to be time consuming and require huge manual effort, making it often impractical and unaffordable in national levels of forest monitoring. In the case of forest inventory and forest tree species classification, the application of remote sensing is constantly increasing because of the enormous availability of airborne, hyperspectral and space borne data [96]. Optical remote sensing techniques, which involves the combination of spatial and spectral information extraction technology offers accurate estimates of forest inventory and biophysical parameters including monitoring Above Ground Biomass(AGB) [61], [97], [98], [52], [99], [100] [101], [102], [103], [104], [105], [106], [107], [108], [109]. Even though the optical remote sensing technologies have extensive application in the extraction of the horizontal parameters of forest with high spatial resolution, they are not able to obtain the vertical structure and distribution of the forests [110], [53], [111], [112]. 
In forest studies, passive and active optical systems failed to estimate the above-ground biomass and leaf area index (LAI) of high biomass ecosystems and could not provide threedimensional pattern of vegetation. It was found that the sensitivity and accuracy of the optical sensors decreased with increasing leaf area index and above ground biomass [113], [72], [114]. Light Detection and Ranging (LiDAR), an active remote sensing system evolved as a promising technology offering advantage over other remote sensing technologies with its unique measurement capability of three-dimensional structures of forests including horizontal as well as vertical forest distribution and can also give direct measurements of individual trees and stands. Integration of ecological research with LiDAR remote sensing reduces the time and effort associated with the measurement of canopy structure, biophysical attributes and thus makes the modelling of global carbon dynamics more effective which are highly important for the ecologists [115], [116], [117], [118], [119], [120]. It is evident from several studies that LIDAR can estimate the structural parameters of forests with high accuracy.

The relevance of the three dimensional structure of forest canopies and hence the need for the advanced technologies for obtaining the detailed spatial information is increasing. We must concentrate on data acquisition of the forest biophysical parameters with consistency, accuracy and cost effectively. It is possible to effectively characterize the structure of forest stands faster and more precisely through the advent of advanced remote sensing technologies. Now, algorithms and programmes are needed to extract suitable parameters of forests from the satellite imageries as well as other remote sensing methods. Even though there are several studies for estimation of biophysical parameters, development of further sophisticated technologies and methods for quantifying the parameters more accurately is substantially desirable. The remote sensing method can monitor forests at different temporal, spatial and spectral resolutions and can be effectively used in large and remote forest region which lacks forest inventory procedures [101]

Review shows that the conventional field methods are inadequate for the parameter extraction since they are time consuming, less accurate and extensive manual work is needed. The review emphasises the requirement of advanced technologies for the extraction of parameters. Remote sensing technologies can meet the requirements and overcome the limitations of the conventional methods. But it was also found that optical and passive remote sensing have also limitations. Therefore, forest based studies should focus on the parameter extraction from active remote sensing data which can estimate the functional attributes for different sections of forestry on a high spatial resolution and characterise both the vertical and horizontal forests distribution accurately. It can also help ecologists and forest managers to characterize the structure of forest stands and monitor forest health and conditions in a quick and precise way.

\section{CONCLUSION}

The review clearly gives a small description of the application of optical remote sensing for the biophysical characterisation of forests. Through optical remote sensing methods, better understanding of forest management and modelling of forest attributes has become possible, in which the conventional data collection techniques have failed. Hence, remote sensing methods can be utilized as a better technology for the management of forest ecology in a most accurate and effective manner. Optical remote sensing including multispectral and hyperspectral imageries is found to have tremendous applications in the estimation of forest spectral characteristics including biomass, vegetation indices, canopy density etc. Traditional field inventory methods and passive remote sensing technologies were found to have several limitations in the forest structural measurements. Review clearly elucidates the need for active remote sensing technology mainly LiDAR for estimation of biophysical characterisation of forests.

\section{Acknowledgement}

The first author is supported by Kerala State Council for Science Technology and Environment (KSCSTE), Thiruvananthapuram, India (Grant No:042/FSHPENV/2015/KSCSTE) in the form of a fellowship for doctoral research.

\section{REFERENCES}

[1] Larjavaara, M., \& Muller-Landau, H. C. (2013). Measuring tree height: a quantitative comparison of two common field methods in a moist tropical forest. Methods in Ecology and Evolution, 4(9), 793-801.

[2] Clark, D. A., \& Clark, D. B. (2001). Getting to the canopy: tree height growth in a neotropical rain forest. Ecology, 82(5), 1460-1472.

[3] Chave, J., Andalo, C., Brown, S., Cairns, M. A., Chambers, J. Q., Eamus, D., ... \& Lescure, J. P. (2005). Tree allometry and improved estimation of carbon stocks and balance in tropical forests. Oecologia, 145(1), 87-99.

[4] Goodwin, A. N. (2004). Measuring tall tree heights from the ground. TASFORESTS-HOBART-, 15, 85-98.

[5] Yoda, K., Suzuki, M., \& Suzuki, H. (2000). Development and evaluation of a new type of optoelectronic dendrometer. IAWA Journal, 21(4), 425-434.

[6] Rhody, B. (1975). A new approach to terrestrial and photographic forest sampling: The use of a panoramic lens. Photogrammetria, 30(2), 75-85.

[7] Binot, J. M., Pothier, D., \& Lebel, J. (1995). Comparison of relative accuracy and time requirement between the caliper, the diameter tape and an electronic tree measuring fork. The Forestry Chronicle, 71(2), 197200.

[8] Parker, R. C., \& Matney, T. G. (1999). Comparison of optical dendrometers for prediction of standing tree volume. Southern Journal of Applied Forestry, 23(2), 100-107.

[9] Weaver, S. A., Ucar, Z., Bettinger, P., Merry, K., Faw, K., \& Cieszewski, C. J. (2015). Assessing the accuracy 
of tree diameter measurements collected at a distance. Croatian Journal of Forest Engineering: Journal for Theory and Application of Forestry Engineering, 36(1), 73-83.

[10] Grosenbaugh, Lewis Randolph. "New tree-measurement concepts: height accumulation, giant tree, taper and shape." (1954).

[11] West, P. W., \& West, P. W. (2009). Tree and forest measurement (Vol. 20). Heidelberg: Springer.

[12] Martin, M. E., Newman, S. D., Aber, J. D., \& Congalton, R. G. (1998). Determining forest species composition using high spectral resolution remote sensing data. Remote Sensing of Environment, 65(3), 249-254.

[13] Van Laar, A., \& Akça, A. (2007). Forest mensuration (Vol. 13). Springer Science \& Business Media.

[14] Sullivan, M. J., Lewis, S. L., Hubau, W., Qie, L., Baker, T. R., Banin, L. F., ... \& Arets, E. (2018). Field methods for sampling tree height for tropical forest biomass estimation. Methods in Ecology and Evolution, 9(5), 1179-1189.

[15] Dimri, Suchita, Pratibha Baluni, and Chandra Mohan Sharma. "GROWING STOCK OF VARIOUS PURE CONIFER FOREST TYPES OF CENTRAL (GARHWAL) HIMALAYA, INDIA." International Journal of Current Research and Review 6.22 (2014): 45.

[16] Devi, L. S., \& Yadava, P. S. (2009). Aboveground biomass and net primary production of semi-evergreen tropical forest of Manipur, north-eastern India. Journal of Forestry Research, 20(2), 151-155.

[17] Hashimotio, T., Kojima, K., Tange, T., \& Sasaki, S. (2000). Changes in carbon storage in fallow forests in the tropical lowlands of Borneo. Forest Ecology and Management, 126(3), 331-337.

[18] Lodhiyal, N., \& Lodhiyal, L. S. (2003). Biomass and net primary productivity of Bhabar Shisham forests in central Himalaya, India. Forest Ecology and Management, 176(1-3), 217-235.

[19] Nelson, B. W., Mesquita, R., Pereira, J. L., De Souza, S. G. A., Batista, G. T., \& Couto, L. B. (1999). Allometric regressions for improved estimate of secondary forest biomass in the central Amazon. Forest ecology and management, 117(1-3), 149-167.

[20] Ravindranath, N. H., \& Ostwald, M. (2008). Generic Methods for Inventory of Carbon Pools (pp. 99-111). Springer Netherlands.

[21] Vashum, K. T., \& Jayakumar, S. (2012). Methods to estimate above-ground biomass and carbon stock in natural forests-A review. J. Ecosyst. Ecogr, 2(4), 1-7.

[22] Brummer, J. E., Nichols, J. T., Engel, R. K., \& Eskridge, K. M. (1994). Efficiency of different quadrat sizes and shapes for sampling standing crop. Journal of Range management, 84-89.

[23] Bonham, C.D. 1989. Measurements of terrestrial vegetation. John Wiley Sons, New York, NY. pp 33-39.
[24] Singh, J. S., Lauenroth, W. K., \& Steinhorst, R. K. (1975). Review and assessment of various techniques for estimating net aerial primary production in grasslands from harvest data. The Botanical Review, 41(2), 181-232.

[25] Montes, N., Gauquelin, T., Badri, W., Bertaudiere, V., \& Zaoui, E. H. (2000). A non-destructive method for estimating above-ground forest biomass in threatened woodlands. Forest Ecology and Management, 130(1-3), 37-46.

[26] Aboal, J. R., Arévalo, J. R., \& Fernández, Á. (2005). Allometric relationships of different tree species and stand above ground biomass in the Gomera laurel forest (Canary Islands). Flora-Morphology, Distribution, Functional Ecology of Plants, 200(3), 264-274.

[27] Hughes, R. F., Kauffman, J. B., \& Jaramillo, V. J. (1999). Biomass, carbon, and nutrient dynamics of secondary forests in a humid tropical region of Mexico. Ecology, 80(6), 1892-1907.

[28] Brown, S., Schroeder, P., \& Birdsey, R. (1997). Aboveground biomass distribution of US eastern hardwood forests and the use of large trees as an indicator of forest development. Forest Ecology and Management, 96(1-2), 37-47.

[29] Lillesand, T., Kiefer, R. W., \& Chipman, J. (2014). Remote sensing and image interpretation. John Wiley \& Sons.

[30] Jensen, J. R. (2009). Remote sensing of the environment: An earth resource perspective 2/e. Pearson Education India.

[31] Sabins, F. F. (2007). Remote sensing: principles and applications. Waveland Press.

[32] Rees, W. G., \& Pellika, P. (2010). Principles of remote sensing. Remote Sensing of Glaciers. London.

[33] Campbell, J. B., \& Wynne, R. H. (2011). Introduction to remote sensing. Guilford Press.

[34] White, J. C., Coops, N. C., Wulder, M. A., Vastaranta, M., Hilker, T., \& Tompalski, P. (2016). Remote sensing technologies for enhancing forest inventories: A review. Canadian Journal of Remote Sensing, 42(5), 619-641.

[35] Tomppo, E., Gschwantner, T., Lawrence, M., McRoberts, R. E., Gabler, K., Schadauer, K., ... \& Cienciala, E. (2010). National forest inventories. Pathways for Common Reporting. European Science Foundation, 541-553.

[36] Alam, M. B., Shahi, C., \& Pulkki, R. (2014). Economic impact of enhanced forest inventory information and merchandizing yards in the forest product industry supply chain. Socio-Economic Planning Sciences, 48(3), 189-197.

[37] Brosofske, K. D., Froese, R. E., Falkowski, M. J., \& Banskota, A. (2013). A review of methods for mapping and prediction of inventory attributes for operational forest management. Forest Science, 60(4), 733-756.

[38] Franklin, S. E. (2001). Remote sensing for sustainable forest management. CRC press. 
[39] McRoberts, R. E., \& Tomppo, E. O. (2007). Remote sensing support for national forest inventories. Remote Sensing of Environment, 110(4), 412-419.

[40] Holmgren, P., \& Thuresson, T. (1998). Satellite remote sensing for forestry planning - a review. Scandinavian Journal of Forest Research, 13(1-4), 90-110.

[41] Lauer, D. T. (1973). Application of remote sensing in forestry.

[42] Kerr, J. T., \& Ostrovsky, M. (2003). From space to species: ecological applications for remote sensing. Trends in ecology \& evolution, 18(6), 299-305.

[43] Ingram, J. C., Dawson, T. P., \& Whittaker, R. J. (2005). Mapping tropical forest structure in southeastern Madagascar using remote sensing and artificial neural networks. Remote Sensing of Environment, 94(4), 491507.

[44] Schlerf, M., Atzberger, C., \& Hill, J. (2005). Remote sensing of forest biophysical variables using HyMap imaging spectrometer data. Remote Sensing of Environment, 95(2), 177-194.

[45] Boyd, D. S., \& Danson, F. M. (2005). Satellite remote sensing of forest resources: three decades of research development. Progress in Physical Geography, 29(1), 126.

[46] Suganuma, H., Abe, Y., Taniguchi, M., Tanouchi, H., Utsugi, H., Kojima, T., \& Yamada, K. (2006). Stand biomass estimation method by canopy coverage for application to remote sensing in an arid area of Western Australia. Forest Ecology and Management, 222(1-3), 75-87.

[47] Smith, A. M., \& Hudak, A. T. (2005). Estimating combustion of large downed woody debris from residual white ash. International Journal of Wildland Fire, 14(3), 245-248.

[48] Roy, D. P., Jin, Y., Lewis, P. E., \& Justice, C. O. (2005). Prototyping a global algorithm for systematic fireaffected area mapping using MODIS time series data. Remote sensing of environment, 97(2), 137-162.

[49] Wooster, M. J. (2002). Small-scale experimental testing of fire radiative energy for quantifying mass combusted in natural vegetation fires. Geophysical Research Letters, 29(21), 23-1.

[50] Roberts, G., Wooster, M. J., Perry, G. L., Drake, N., Rebelo, L. M., \& Dipotso, F. (2005). Retrieval of biomass combustion rates and totals from fire radiative power observations: Application to southern Africa using geostationary SEVIRI imagery. Journal of Geophysical Research: Atmospheres, 110(D21).

[51] Lentile, L. B., Holden, Z. A., Smith, A. M., Falkowski, M. J., Hudak, A. T., Morgan, P., ... \& Benson, N. C. (2006). Remote sensing techniques to assess active fire characteristics and post-fire effects. International Journal of Wildland Fire, 15(3), 319-345.

[52] Zheng, D., Rademacher, J., Chen, J., Crow, T., Bresee, M., Le Moine, J., \& Ryu, S. R. (2004). Estimating aboveground biomass using Landsat 7 ETM+ data across a managed landscape in northern Wisconsin, USA. Remote sensing of environment, 93(3), 402-411.

[53] Foody, G. M., Cutler, M. E., Mcmorrow, J., Pelz, D., Tangki, H., Boyd, D. S., \& Douglas, I. (2001). Mapping the biomass of Bornean tropical rain forest from remotely sensed data. Global Ecology and Biogeography, 10(4), 379-387.

[54] Lu, D. (2005). Aboveground biomass estimation using Landsat TM data in the Brazilian Amazon. International Journal of Remote Sensing, 26(12), 2509-2525.

[55] Chave, J., Olivier, J., Bongers, F., Châtelet, P., Forget, P. M., Van der Meer, P., ... \& Charles-Dominique, P. (2008). Above-ground biomass and productivity in a rain forest of eastern South America. Journal of Tropical Ecology, 24(4), 355-366.

[56] Dovey, S. B. (2009). Estimating biomass and macronutrient content of some commercially important plantation species in South Africa. Southern Forests, 71(3), 245-251.

[57] Henry, M., Picard, N., Trotta, C., Manlay, R., Valentini, R., Bernoux, M., \& Saint André, L. (2011). Estimating tree biomass of sub-Saharan African forests: a review of available allometric equations. Silva Fennica, 45(3B), 477-569.

[58] Reese, H., Nilsson, M., Sandström, P., \& Olsson, H. (2002). Applications using estimates of forest parameters derived from satellite and forest inventory data. Computers and Electronics in Agriculture, 37(1-3), 37-55.

[59] Jayakumar, S., Ramachandran, A., Bhaskaran, G., \& Heo, J. (2009). Forest dynamics in the Eastern Ghats of Tamil Nadu, India. Environmental management, 43(2), 326-345.

[60] Roberts, J. W., Tesfamichael, S., Gebreslasie, M., Van Aardt, J., \& Ahmed, F. B. (2007). Forest structural assessment using remote sensing technologies: an overview of the current state of the art. Southern Hemisphere Forestry Journal, 69(3), 183-203.

[61] Wulder, M. (1998). Optical remote-sensing techniques for the assessment of forest inventory and biophysical parameters. Progress in physical Geography, 22(4), 449-476.

[62] Cohen, W. B., \& Goward, S. N. (2004). Landsat's role in ecological applications of remote sensing. AIBS Bulletin, 54(6), 535-545.

[63] Karlson, M., Ostwald, M., Reese, H., Sanou, J., Tankoano, B., \& Mattsson, E. (2015). Mapping tree canopy cover and aboveground biomass in SudanoSahelian woodlands using Landsat 8 and random forest. Remote Sensing, 7(8), 10017-10041.

[64] Dube, T., \& Mutanga, O. (2015). Evaluating the utility of the medium-spatial resolution Landsat 8 multispectral sensor in quantifying aboveground biomass in uMgeni catchment, South Africa. ISPRS Journal of Photogrammetry and Remote Sensing, 101, 36-46.

[65] Gao, H., Wang, L., Jing, L., \& Xu, J. (2016, April). An effective modified water extraction method for Landsat- 
8 OLI imagery of mountainous plateau regions. In IOP Conference Series: Earth and Environmental Science (Vol. 34, No. 1, p. 012010). IOP Publishing.

[66] Lefsky, M. A., Cohen, W. B., \& Spies, T. A. (2001). An evaluation of alternate remote sensing products for forest inventory, monitoring, and mapping of Douglasfir forests in western Oregon. Canadian journal of forest research, 31(1), 78-87.

[67] Tomppo, E., Nilsson, M., Rosengren, M., Aalto, P., \& Kennedy, P. (2002). Simultaneous use of Landsat-TM and IRS-1C WiFS data in estimating large area tree stem volume and aboveground biomass. Remote Sensing of Environment, 82(1), 156-171.

[68] Maselli, F., Chirici, G., Bottai, L., Corona, P., \& Marchetti, M. (2005). Estimation of Mediterranean forest attributes by the application of $\mathrm{k}-\mathrm{NN}$ procedures to multitemporal Landsat ETM+ images. International Journal of Remote Sensing, 26(17), 3781-3796.

[69] Heiskanen, J. (2006). Estimating aboveground tree biomass and leaf area index in a mountain birch forest using ASTER satellite data. International Journal of Remote Sensing, 27(6), 1135-1158.

[70] Price, J. C., \& Bausch, W. C. (1995). Leaf area index estimation from visible and near-infrared reflectance data. Remote Sensing of Environment, 52(1), 55-65.

[71] Foody, G. M., Boyd, D. S., \& Cutler, M. E. (2003). Predictive relations of tropical forest biomass from Landsat TM data and their transferability between regions. Remote sensing of environment, 85(4), 463-474.

[72] Turner, D. P., Cohen, W. B., Kennedy, R. E., Fassnacht, K. S., \& Briggs, J. M. (1999). Relationships between leaf area index and Landsat TM spectral vegetation indices across three temperate zone sites. Remote sensing of environment, 70(1), 52-68.

[73] Brown, L., Chen, J. M., Leblanc, S. G., \& Cihlar, J. (2000). A shortwave infrared modification to the simple ratio for LAI retrieval in boreal forests: An image and model analysis. Remote sensing of environment, 71(1), $16-25$.

[74] Eklundh, L., Harrie, L., \& Kuusk, A. (2001). Investigating relationships between Landsat ETM+ sensor data and leaf area index in a boreal conifer forest. Remote sensing of Environment, 78(3), 239-251.

[75] Jensen, R. R., \& Binford, M. W. (2004). Measurement and comparison of Leaf Area Index estimators derived from satellite remote sensing techniques. International Journal of Remote Sensing, 25(20), 4251-4265.

[76] Cohen, W. B., Maiersperger, T. K., Gower, S. T., \& Turner, D. P. (2003). An improved strategy for regression of biophysical variables and Landsat ETM+ data. Remote Sensing of Environment, 84(4), 561-571.

[77] Mäkelä, H., \& Pekkarinen, A. (2001). Estimation of timber volume at the sample plot level by means of image segmentation and Landsat TM imagery. Remote Sensing of Environment, 77(1), 66-75.

[78] Franco-Lopez, H., Ek, A. R., \& Bauer, M. E. (2001). Estimation and mapping of forest stand density, volume, and cover type using the k-nearest neighbors method. Remote sensing of Environment, 77(3), 251-274.

[79] Tomppo, E., \& Heikkinen, J. (1999). National forest inventory of Finland-past, present and future. Statistics, registries and research-experiences from Finland, 89-108.

[80] Remmel, Tarmo K., Ferenc Csillag, Scott Mitchell, and Michael A. Wulder. "Integration of forest inventory and satellite imagery:: a Canadian status assessment and research issues." Forest Ecology and Management 207, no. 3 (2005): 405-428.

[81] McRoberts, R. E. (2006). A model-based approach to estimating forest area. Remote Sensing of Environment, 103(1), 56-66.

[82] Dandois, J. P., \& Ellis, E. C. (2013). High spatial resolution three-dimensional mapping of vegetation spectral dynamics using computer vision. Remote Sensing of Environment, 136, 259-276.

[83] Dymond, C. C., Mladenoff, D. J., \& Radeloff, V. C. (2002). Phenological differences in Tasseled Cap indices improve deciduous forest classification. Remote Sensing of Environment, 80(3), 460-472.

[84] Hansen, A. J., Rasker, R., Maxwell, B., Rotella, J. J., Johnson, J. D., Parmenter, A. W., ... \& Kraska, M. P. (2002). Ecological Causes and Consequences of Demographic Change in the New West: As natural amenities attract people and commerce to the rural west, the resulting land-use changes threaten biodiversity, even in protected areas, and challenge efforts to sustain local communities and ecosystems. AIBS Bulletin, 52(2), 151-162.

[85] Kosaka, N., Akiyama, T., Tsai, B., \& Kojima, T. (2005, July). Forest type classification using data fusion of multispectral and panchromatic high-resolution satellite imageries. In Geoscience and Remote Sensing Symposium, 2005. IGARSS'05. Proceedings. 2005 IEEE International (Vol. 4, pp. 2980-2983). IEEE.

[86] Wang, L., Sousa, W. P., \& Gong, P. (2004). Integration of object-based and pixel-based classification for mapping mangroves with IKONOS imagery. International Journal of Remote Sensing, 25(24), 56555668.

[87] Meng, J., Li, S., Wang, W., Liu, Q., Xie, S., \& Ma, W. (2016). Estimation of forest structural diversity using the spectral and textural information derived from SPOT-5 satellite images. Remote Sensing, 8(2), 125.

[88] Borengasser, M., Hungate, W. S., \& Watkins, R. (2007). Hyperspectral remote sensing: principles and applications. CRC press.

[89] Goetz, A. F., \& Landauer Jr, F. P. (1979). U.S. Patent No. 4,134,683. Washington, DC: U.S. Patent and Trademark Office.

[90] Tong, Q., Xue, Y., \& Zhang, L. (2014). Progress in hyperspectral remote sensing science and technology in China over the past three decades. IEEE Journal of Selected Topics in Applied Earth Observations and Remote Sensing, 7(1), 70-91. 
[91] Rock, B. N., Hoshizaki, T., \& Miller, J. R. (1988). Comparison of in situ and airborne spectral measurements of the blue shift associated with forest decline. Remote Sensing of Environment, 24(1), 109127.

[92] Miller, J. R., Wu, J., Boyer, M. G., Belanger, M., \& Hare, E. W. (1991). Seasonal patterns in leaf reflectance red-edge characteristics. International Journal of Remote Sensing, 12(7), 1509-1523.

[93] Sampson, P. H., Zarco-Tejada, P. J., Mohammed, G. H., Miller, J. R., \& Noland, T. L. (2003). Hyperspectral remote sensing of forest condition: Estimating chlorophyll content in tolerant hardwoods. Forest science, 49(3), 381-391.

[94] Zhang, Z., Ni, W., Fu, A., Guo, Z., Sun, G., \& Wang, D. (2008). Estimation of forest structural parameters from Lidar and SAR data. Int Arch Photogramm, Remote Sens Spat Inf Sci, 37, 1121-1126.

[95] Govender, M., Chetty, K., \& Bulcock, H. (2007). A review of hyperspectral remote sensing and its application in vegetation and water resource studies. Water Sa, 33(2).

[96] Fassnacht, F. E., Latifi, H., Stereńczak, K., Modzelewska, A., Lefsky, M., Waser, L. T., ...\& Ghosh, A. (2016). Review of studies on tree species classification from remotely sensed data. Remote Sensing of Environment, 186, 64-87.

[97] Köhl, M., Magnussen, S. S., \& Marchetti, M. (2006). Sampling methods, remote sensing and GIS multiresource forest inventory. Springer Science \& Business Media.

[98] Weishampel, J. F., Ranson, K. J., \& Harding, D. J. (1996). Remote sensing of forest canopies. Selbyana, 614.

[99] Straub, C., Dees, M., Weinacker, H., \& Koch, B. (2009). Using airborne laser scanner data and CIR orthophotos to estimate the stem volume of forest stands. Photogrammetrie-Fernerkundung-Geoinformation, 2009(3), 277-287.

[100] Mitchard, E. T., Saatchi, S. S., Woodhouse, I. H., Nangendo, G., Ribeiro, N. S., Williams, M., ...\& Meir, P. (2009). Using satellite radar backscatter to predict above-ground woody biomass: A consistent relationship across four different African landscapes. Geophysical Research Letters, 36(23).

[101] Patenaude, G., Milne, R., \& Dawson, T. P. (2005). Synthesis of remote sensing approaches for forest carbon estimation: reporting to the Kyoto Protocol. Environmental Science \& Policy, 8(2), 161-178.

[102] Kajisa, T., Murakami, T., Mizoue, N., Top, N., \& Yoshida, S. (2009). Object-based forest biomass estimation using Landsat ETM+ in Kampong Thom Province, Cambodia. Journal of Forest Research, 14(4), 203-211.

[103] Basuki, T. M., Skidmore, A. K., Hussin, Y. A., \& Van Duren, I. (2013). Estimating tropical forest biomass more accurately by integrating ALOS PALSAR and
Landsat-7 ETM+ data. International journal of remote sensing, 34(13), 4871-4888.

[104] Lu, D., Chen, Q., Wang, G., Moran, E., Batistella, M., Zhang, M., ... \& Saah, D. (2012). Aboveground forest biomass estimation with Landsat and LiDAR data and uncertainty analysis of the estimates. International Journal of Forestry Research, 2012.

[105] Timothy, D., Onisimo, M., \& Riyad, I. (2016). Quantifying aboveground biomass in African environments: A review of the trade-offs between sensor estimation accuracy and costs. Tropical Ecology, 57(3), 393-405.

[106] Wang, K., Xiang, W. N., Guo, X., \& Liu, J. (2012). Remote Sensing of Forestry Studies. In Global Perspectives on Sustainable Forest Management. InTech.

[107] Ferreira, M. P., Zortea, M., Zanotta, D. C., Shimabukuro, Y. E., \& de Souza Filho, C. R. (2016). Mapping tree species in tropical seasonal semideciduous forests with hyperspectral and multispectral data. Remote Sensing of Environment, 179, 66-78.

[108] Babcock, C., Finley, A. O., Cook, B. D., Weiskittel, A., \& Woodall, C. W. (2016). Modeling forest biomass and growth: Coupling long-term inventory and LiDAR data. Remote Sensing of Environment, 182, 1-12.

[109] Corona, P., Cartisano, R., Salvati, R., Chirici, G., Floris, A., Di Martino, P., ... \& Torresan, C. (2012). Airborne Laser Scanning to support forest resource management under alpine, temperate and Mediterranean environments in Italy. European Journal of Remote Sensing, 45(1), 27-37.

[110] Hudak, A. T., Strand, E. K., Vierling, L. A., Byrne, J. C., Eitel, J. U., Martinuzzi, S., \& Falkowski, M. J. (2012). Quantifying aboveground forest carbon pools and fluxes from repeat LiDAR surveys. Remote Sensing of Environment, 123, 25-40.

[111] Lefsky, M. A., Cohen, W. B., Acker, S. A., Spies, T. A., Parker, G. G., \& Harding, D. (1998, July). Lidar remote sensing of forest canopy structure and related biophysical parameters at HJ Andrews experimental forest, Oregon, USA. In Geoscience and Remote Sensing Symposium Proceedings, 1998. IGARSS'98. 1998 IEEE International (Vol. 3, pp. 1252-1254). IEEE.

[112] Koch, Barbara. "Status and future of laser scanning, synthetic aperture radar and hyperspectral remote sensing data for forest biomass assessment." ISPRS Journal of Photogrammetry and Remote Sensing 65.6 (2010): 581-590.

[113] Carlson, T. N., \& Ripley, D. A. (1997). On the relation between NDVI, fractional vegetation cover, and leaf area index. Remote sensing of Environment, 62(3), 241252.

[114] Waring, R. H., Way, J., Hunt, E. R., Morrissey, L., Ranson, K. J., Weishampel, J. F., ... \& Franklin, S. E. (1995). Imaging radar for ecosystem studies. BioScience, 45(10), 715-723. 
[115] Popescu, S. C., Zhao, K., Neuenschwander, A., \& Lin, C. (2011). Satellite lidar vs. small footprint airborne lidar: Comparing the accuracy of above ground biomass estimates and forest structure metrics at footprint level. Remote Sensing of Environment, 115(11), 2786-2797.

[116] Pizaña, J. M. G., Hernández, J. M. N., \& Romero, N. C. (2016). Remote Sensing-Based Biomass Estimation. In Environmental Applications of Remote Sensing. InTech.

[117] Glenn, N. F., Spaete, L. P., Sankey, T. T., Derryberry, D. R., Hardegree, S. P., \& Mitchell, J. J. (2011). Errors in LiDAR-derived shrub height and crown area on sloped terrain. Journal of Arid Environments, 75(4), 377-382.

[118] Wang, D., Xin, X., Shao, Q., Brolly, M., Zhu, Z., \& Chen, J. (2017). Modeling Aboveground Biomass in Hulunber Grassland Ecosystem by Using Unmanned Aerial Vehicle Discrete Lidar. Sensors, 17(1), 180.

[119] Vastaranta, M., Kankare, V., Holopainen, M., Yu, X., Hyyppä, J., \& Hyyppä, H. (2012). Combination of individual tree detection and area-based approach in imputation of forest variables using airborne laser data. ISPRS Journal of Photogrammetry and Remote Sensing, 67, 73-79

[120] Latifi, H., Fassnacht, F. E., Hartig, F., Berger, C., Hernández, J., Corvalán, P., \& Koch, B. (2015). Stratified aboveground forest biomass estimation by remote sensing data. International Journal of Applied Earth Observation and Geoinformation, 38, 229-241. 